A substantial start has been made. The Mas- or eight weeks. Under usual conditions this sachusetts central state institution has been in man would not relapse for four or five months, part built, out-patient departments have been therefore the report of the result of hospital established and the coöperation of the hospitals treatment should be suspended for a consideris assured. To the trustees and to those of us able period; at least, a final report on the case who are interested in the proposition the real in- should not be made until one or more of the centive for the contribution of our work is our man's episodical attacks of drinking have been conviction that the public believe in the integ- successfully combated. On the other hand, if a rity and stability of the system as planned six vears ago.

man who had been a regular or irregular drink-

I er before his hospital treatment, is abstinent fail feel that my paper would be incomplete if I for a considerable period after his discharge failed to describe our method of treatment. Be- from the hospital (we have tentatively placed lieving as we do, that the inebriate condition this period at six months), we are justified in has for its basis a distorted mentalization, our efforts are directed in an endeavor to interest the patient in his individual case and, having accomplished this, to make the interest self-sustaining. Our experience has shown us that the success of hospital treatment depends upon:--

(a) The ability of the patient to coöperate in treatment.

(b) Our ability to introduce into the patient's mentality some tangible substitute for the desire for artificial stimulation.

Such a result is brought about by attention to the patient's mental and physical hygiene, and necessarily depends.on the educational measures inaugurated at the hospital and continued by the patient after he leaves the institution. The treatment must necessarily be considered as in the realm of physiologic therapeutics, which is supplemented by the simplest form of suggestion. The suggestion is really an auto-suggestion, the result of a correlation of impressions which the patient receives from his association with the physicians and from his relation to the hospital environment. The physician is concerned in an analysis of the individual case, which is made possible by encouraging the patient to coöperate in his own recovery, by strengthening his self control.

I have reserved for my concluding paragraphs an account of our work extending over a period of five years. Considering the result of hospital treatment, it must be borne in mind that the total number of discharges is considered. No attempt has been made to differentiate cases. Each case has been considered individually, the following conditions determining the final report of the result of treatment.

1. The type of inebriety, divisible for practical purposes into three classes:-

(a) The regular drinker,-one accustomed to the use of stimulants daily.

(b) The irregular drinker,-one accustomed to the use of stimulants at short intervals.

(c) The periodical drinker, -one accustomed to drink at periodic intervals, periods of months or years elapsing between the periods of insobriety.

Thus a man whose period of drinking occurs at intervals of six months may be admitted to the hospital in a state of acute intoxication, recuperate rapidly and leave the hospital in six his bone grafting operation for Pott's disease,

2: The conduct and attitude of the patient after his discharge from the hospital. Under this caption we consider the ability of the man to earn his livelihood, and his success in readjusting himself to society.

3. The willingness of the patient to coöperate with hospital authorities after his discharge from the hospital.

Guided by these rules, we have carefully investigated the present condition of all patients discharged and have made careful comparative
tests.

The following figures, therefore, have been compiled after continual and prolonged observation of discharged patients; these do not include patients who have not been discharged for a maximum period of six months. During the past five years 1174 patients have been investigated as above described. Out of this 1174 , approximately 753 , or $64 \%$, are today working and either totally abstinent or drinking so little as not to interfere with their work. Practically all of these men had, before coming to the hospital, dropped below the class of the self-supporting. The successful treatment of the inebriate in a state institution may, therefore, be said to be dependent, first, on an appreciation of the true nature of the condition; second, on a realization that the inebriate, dependent on the degree and intensity of the condition, demands specialized treatment; third, the necessity for active and continued coöperation with those interests which are genuinely concerned in the problem; fourth, diligent and consistent work and an adherence to the principle established by a definite method of control; and lastly, the education of the public to a proper realization of the status of the institution to the community.

\title{
AN ELECTRO-MOTOR BONE OUTFIT AND TECHNIC OF ITS USAGE.
}

By Fred H. ALbeE, M.D., F.A.C.S., New York City,

Professor of Orthopedic Surgery, New York PostGraduate Hospital and University of Vermont.

UN'II 1911, when the author finst began to do 


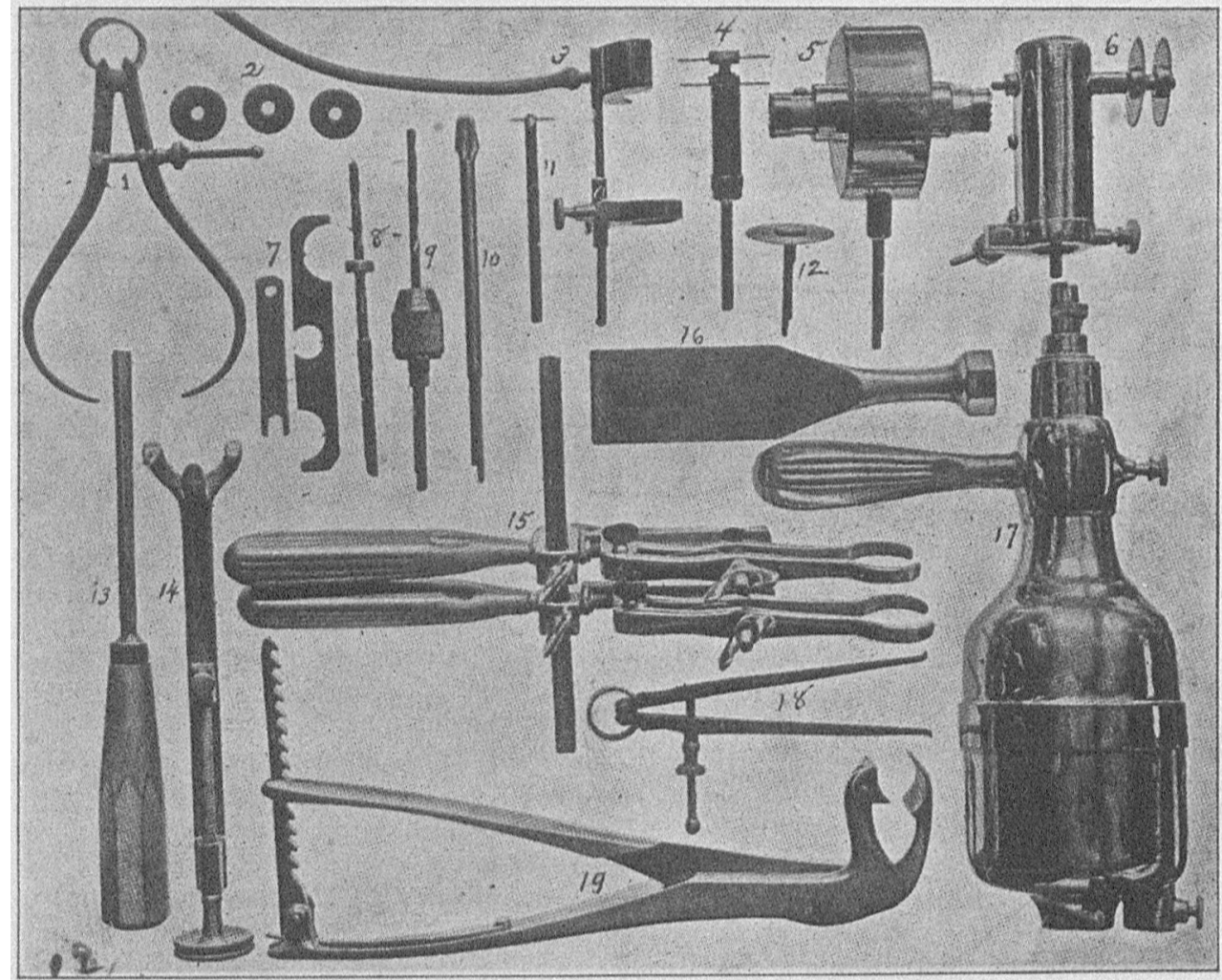

Flli. 1.-Author's armamentarium for bone work.

1. Calipers. 2. Doyen wushers or gunrds for motor suw. 3. Spray und guard for saw. 4. Twin waw. 5. Dowelling instrument or lathe with cutters of two sizes in pluce. 6. Right angle twin saw. 7. Wrenches for twin saw und drill chuck. 8. Drill with guard to prevent it penetrating too deeply. 8. Drill chuck and small drili ill place. 10. Burr for drilling fructured neck of femur for peg graft. 11. Small circular saw. 12. Large saw. 13. Carver's gouge. 14. Lowman fructure clamp. 15. Berg fracture clump. 18. Wide osteotome for splitting spinous processes for the insertion of bone graft for Pott's disease. 17. Surgical electric motor. 18. Compasses. 10. Lambotte fracture clump, large and small.

the bone transplant had been so infrequently In removing the graft with the chisel and malused as a surgical agent that no special technic let, the graft must many times be handled and had been developed for its removal. The electric shaped after its removal, whereas with the cirmotor circular saw (Doyen) had been used for cular motor-driven saw a pattern marked in the skull work, driven by either a flexible shaft from periosteum with a scalpel can be followed accua motor on a nearby stand, or by the Hartley- rately and the graft shaped in situ during its Kenyon apparatus, where the cutting tool is at- removal. The graft pattern is usually obtained tached directly to the motor shaft, - and, so by bending a flexible probe or leaden bar into far as the authpr is aware, it had not been used the prepared graft-bed, whose shape is transin any systematic way for the removal or the ferred to the tibial surface from which the modelling of bone transplants.

The author began his spinal work by removing the graft from the tibia with chisel and mallet, and later others made use of the Gigli saw. It was soon found that these methods were not only slow and inaccurate, but that they presented the dangers of bruising, cracking, or fracturing the graft or tibia, or both. This is especially true in adult patients, on account of the brittleness and thickness of the cortex. In the child, on account of the small diameter of the bone, the danger of fracture is evident, although the graft is obtained by means of hand tools with much less difficulty and much less likelihood of fracturing it.

Also, in obtaining grafts 8 in. or more in length, it was found that the hand-tool methods were crude, requiring too much time, tiring the surgeon, and unnecessarily shocking the patient. in view of the fact that Ollier, in 1858 , from ex- 
tensive animal experiments and surgical work,although working in the pre-antiseptic era,furnished abundant evidence that the autoplastic bone graft survived and lived when consist. ing of cortex, periosteum, and endosteum, and implanted into a bony defect where it had function to perform.

As in many other fields of endeavor, electric power has been the chief means of placing this valuable agent at the disposal of the surgeon. In recent years the generalization of the use of electricity for lighting, heating, and power purposes in most hospitals, private dwellings, etc., has also been a potent influence, and has enabled the surgeon always to be in reach of the necessary power for operating his motor outfitwhether he is operating in the city, suburban hospital, or private dwelling. The electric automobile or storage battery can also be made to furnish a movable source of supply, which can be utilized at any time, or place

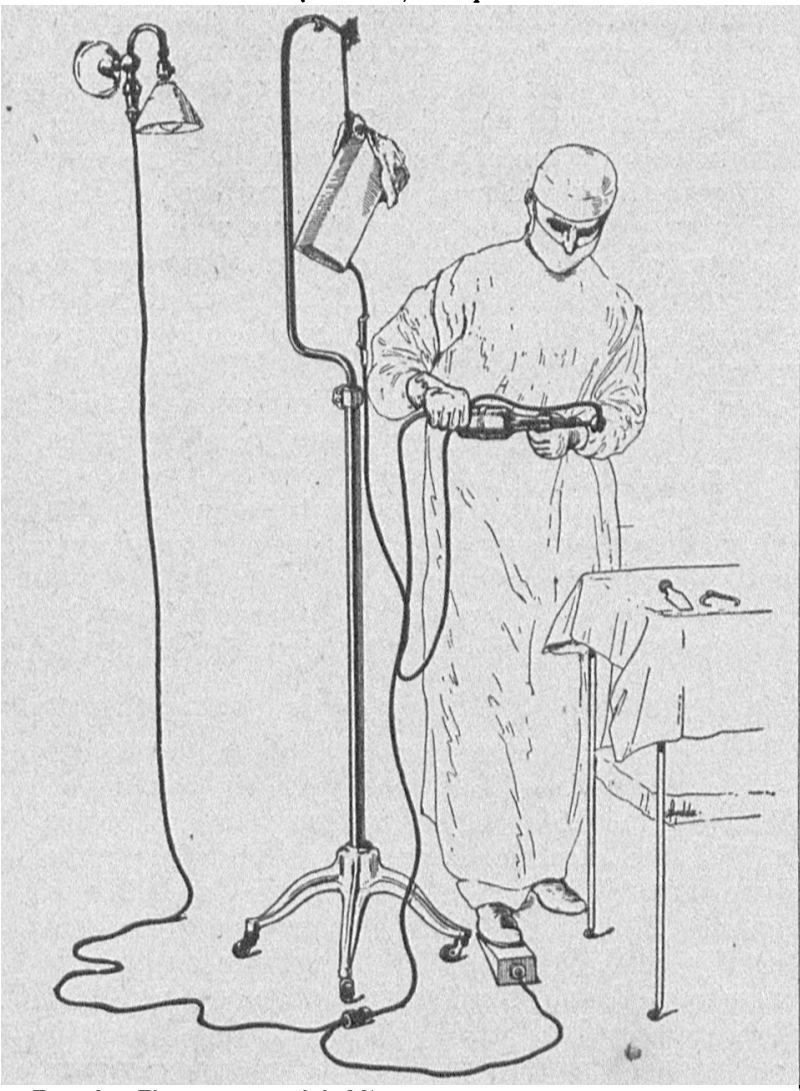

FIG. 2.-The manner of holding the motor saw. The connecting wire to the electric wall fixture. The foot switch control. The sterilizable connecting wire to the motor. The sterilized rubber tube connecting the tank of normal saline solution and the opray attachment above the saw. The author's broad thin osteotome for splitting the spinous processes and the calipers for determining the length of the graft are on instrument table.

The ideal surgical electro-motor outfit should measure up to the following requirements:-

1. It should permit of the thorough sterilization of every, part which comes in contact with the surgeon or the field of operation, including the electric cable for transmitting the power.

2. It should permit of ready application to all types of osteoplasty, whether situated super- ficially or in a deep wound; whether the work to be done is the procuring of the graft, the preparation of its bed, the drilling of holes, the removal of bone for the correction of deformity or disease, or to allow the proper approximation and alignment of bone fragments in cases of tracture.

3. It should permit accurate control and guidance of the motor cutting tool in all wounds and at all angles.

4. It should permit easy and convenient control of the electric current.

5. It should be light in weight, small in bulk, and permit of easy transportation.

6. The motor should be universal and adapted to all types of electric current.

7. The motor instruments,-saws of different 1 ypes, drills, dowel shapers, etc.,-should be held in place in the motor by an automatic catch favoring their speedy interchange.

8. The motor-cutting tools should be constructed similarly to those long-used by the artisan for working hard materials, and should be of sufficient variety to meet every requirement of bone carpentry. The twin saw for inlay work should be so constructed that it can be readily adjusted, - to the fraction of a millimetre, - by the gloved hands of the surgeon at the operating table. The dowel cutters, with drills of corresponding diameters, should vary in size sufficiently to meet all requirements.

9. The motor should furnish enough power to drive rapidly a saw or large drill through the thickest human cortex without tendency to stall.

The author's outfit, described in this chapter, has been carefully devised and perfected with the coöperation of the Kny-Scheerer Company, to fulfil all of the above-mentioned requirements. The motor tool is attached directly to the motor shaft; the motor is covered by an adjustable sterilizable shell, enabling the surgeon to hold the motor in his hands while the tool is cutting: the weight of the outfit has been found ta be an advantage rather than a detriment in its application. and it is believed that it completely fulfils every demand.

\section{DESCRIPTION OF OUTFIT.}

The author s electric operating bone set consists of a small universal motor, i.e. one which will operate without readjustment on all types of electric currents, such as direct, alternating. and of varying cycles. If it is to be used on a 220 volt current, a 100 c.p. 220 volt lamp should be placed in series with motor. Electrical engineers have found it impossible to construct a light motor which will resist deterioration from repeated boiling of the motor itself, or any other safe type of sterilization. Both the insulating material and the carbon brushes are liable to disintegration from repeated subjection to heat. Therefore, the Hartley-Kenyon method of removable, sterilizable shells has been adopted, as it seemed by all means the most desirable. 
The apparatus consists of a small portable motor with a sterilizable shell which is divided into two parts, so that it can be removed for boiling. A guide handle, which also can be boiled, is adjusted on and at right angles to the small end of the motor over the shell.

A foot switch is supplied to make and break the electric circuit. A long electro-conducting cord is provided to transmit the current from the source of supply. In one end of the cable is a fitting, to be inserted into the electric supply, and on the other end is a connection for the foot switch. Midway between the two terminals, a connecting block is mounted, into which is inserted the connecting cord leading to the operating motor. This connecting cord has fitted onto one end of it a metal tube and counection for the motor, and is the only portion of the electric cable to be boiled.

The foot switch can be used with either side upward. If the corrugated rubber side is upward, the connection is made by pushing down with the foot. If the other side is used upward, the foot should be placed over the entire switch. and by depressing, or allowing the aluminum lever to rise by moving the heel up and down, the current is turned on or off. An important feature of the foot switch is that it contains a speed regulator, so that the more gently the surgeon presses the pedal the slower the tool turns. This is especially a great advantage in starting to drill hard bone. When the pedal is completely depressed the motor is at full speed.

\section{CUTTING INSTRUMENTS}

The single saw,-about 11/4 inches in diameter,-with Doyen graduated washers or guards, is used more than any other of the cutting tools. These saws are of the best steel and are very thin, and are held on the shaft by means of nuts which allow the saw blades to be changed when they become dulled.

The twin saw is so constructed that it can be adjusted to any desired width, even to the fraction of a millimetre. It consists of 2 single saws, which can be used isingly or together. Each saw is mounted on a separate shaft, one of which is hollow, so that the other shaft can be inserted into it and so bring the saws at any distance apart that may be desired, according to the size of the bone being operated upon and the width of the graft or gutter to be formed.

In determining the size of the inlay or the gutter, the saw teeth are placed on the bone in the manner of a compass or calipers in order to determine the width of the inlay or gutter, and, with the saws undisturbed, the shaft of the proximal saw is prevented from turning by placing the accompanying wrench or a heavy clamp on the flat-sided 'end of the shaft, while the operator locks the saws together by turning the saw on this shaft away from him by protecting his gloved right hand with a piece of gauze over the saw teeth.
The dowel instrument or lathe is fastened into the motor by the automatic catch, precisely as are the other cutting tools. Its speed of rotation is reduced about 10 times by steel gears.

The size of the bone graft dowel or nail is regulated by the size of the cutter, which is ad. justed in the lathe. The largest cutter is for turning out a bone graft spike for a fracture of the neck of the femur. The smallest one is for making pegs to hold inlay grafts in place. The medium-sized cutter is for making graft nails for pinning the scaphoid to the head of the ustragalus in an arthrodesis for advanced flatfoot, or other condition.

The dowel-shaper is used by first inserting it into the motor, and then placing the apparatus parallel with and on the edge of the instrument table. While the assistant steadies the motor and lathe by gently pressing the same on the table, the operator, holding with a strong clamp the strip of bone to be shaped, pushes it into the dowel cutter. When withdrawn, it is a perfectly round dowel, and is ready to be driven into the drill hole made by a drill of a size corresponding to the dowel-cutter used. The strip of bone is obtained by means of the single or the twin saw. The small sau is used for cutting the ends of the inlay graft or the strip of bone which is being removed to produce a gutter. On account of its small diameter ( $3 / 4$ in.) the saw does not encroach into the gutter walls while it is cutting across the inlay.

The guard with spray is an important attachment. It is connected by a sterile rubber tube with a douche bag suspended over the operating table, and maintains a constant spray of saline solution on the saw, preventing friction, heat, and flying of the solution.

The tuist drills are of the type used by the machinist for drilling metal.

\section{STFRIIJIZATION.}

The parts to be sterilized are first removed from the motor by releasing the plunger on the end of the electric cable, so as to allow it to come out. This part of the electric cable, from the motor to the black rubber union on the contacting cord, is boiled. The handle and shells are removed and, together with the cutting tools, sterilized by boiling. The part into which the cutting instruments are inserted is removed from the motor, with the long part of the sterilized shell. This is the part which contains the automatic catch. A little sterile vaseline is placed in the motor shaft opening, and the motor is laid aside until the sterilizable parts are ready to be readjusted.

After sterilization, the operator picks up the long part of the shell with his gloved hand and places it on the corresponding end of the motor, which the nurse holds with the small end up. The nurse holds the large end of the motor in the palm of her hand while the surgeon fastens the shell to the other end by turning the shell to- 


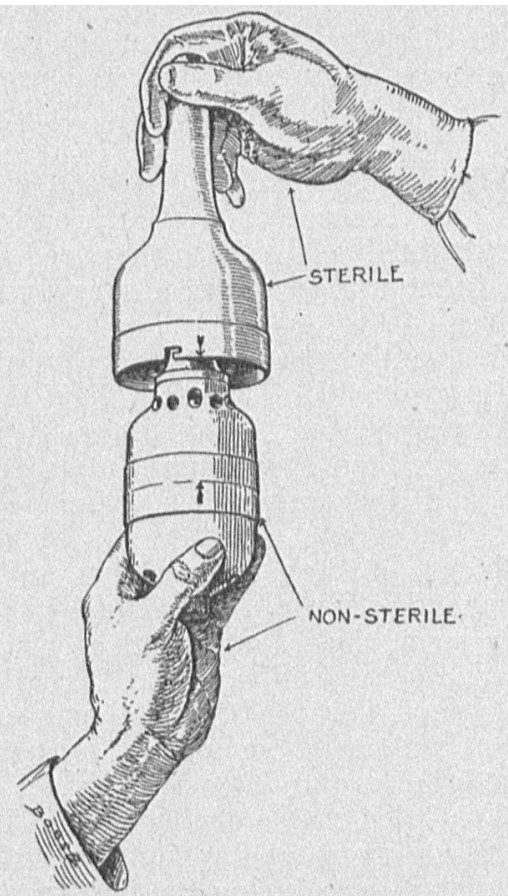

FIa. 3.-Metnod of putting author's motor outflt together. The sterile shell is turned to the left until it can be turned no further and the arrow on the shell comes in line with the arrow on the motor. The surgeon then has control of the motor and turus it over (see Fig. 4).

ward the right as far as it will go, or until the dart on the shell comes opposite the dart on the motor. The operator can then manage the motor alone by grasping the sterile half shell, which is firmly secured to the motor. The second half of the shell is placed over the other end of the motor and is locked in place to the first half shell by a bayonet fitting. The guide handle is placed over the neck of the motor and securely

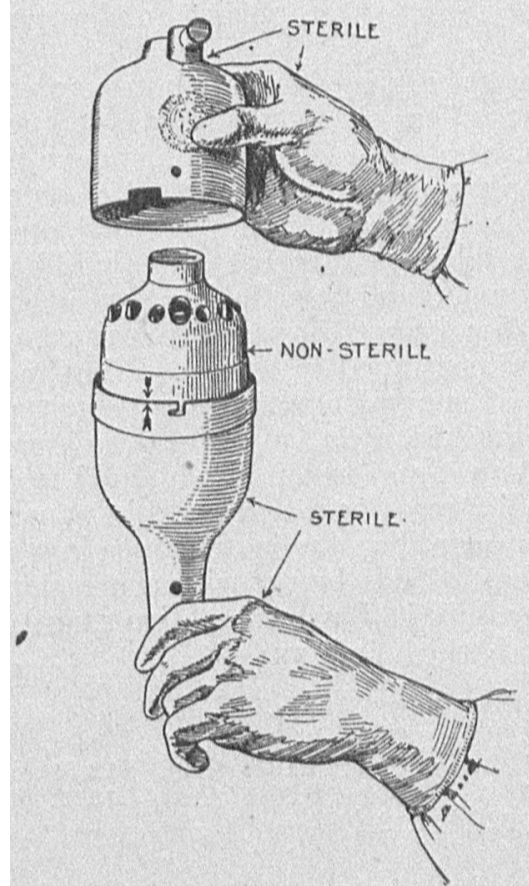

Fio. 4.--While the surgeon bolds the motor by the sterile shell aiready attached, he locks the other half shell in place. fastened by the set screw. The connecting plunger on the side of the electric cable is then inserted through the sleeve on the shell into the motor. This portion of the electric cable, with its metal tube and block connectors, is especially constructed to withstand sterilization by boiling. The corresponding connector is next inserted into the black connecting block in the central portion of the cable leading from the socket of electric supply to the foot switch which the nurse has previously connected and arranged with the foot switch in a convenient position for the surgeon's controlling foot while he is operating. The motor is then ready for use. The saws or the cutting tools are inserted by turning them over a little to the right or the left, while the knurled ring on the end of the shaft is pressed in by the operator's thumb, or until the spring engages the slot on the side of the shaft of the instrument. The cutting tool is unlocked by pressing the knurled ring on the end of the shaft at the same time that the instrument is withdrawn. The action of the motor is controlled by the foot switch which makes and breaks the electric circuit, and the surgeon thus has the uninterrupted use of both hands and the most precise control of the cutting in. struments.

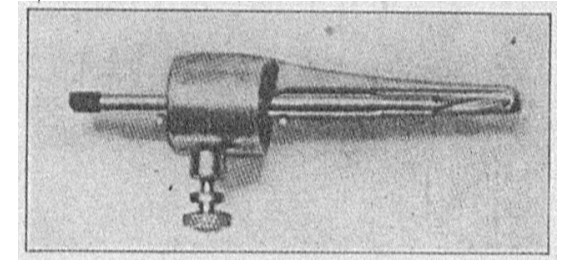

Fio. 5.-Illustration of Martel's attachment to author's electrical surgical outfit for lanincetomy and skull work. The tool is used to cut away the laminae and the blunt shoe at the end prevents to cut away the laminae and the blunt shoe at the end prevents
any injury to the dura or cord. The operation is mirch hastened any injury to the dura or cord. The operation is mich hastened
thereby. A skull flap is produced and timed up in a similar way.

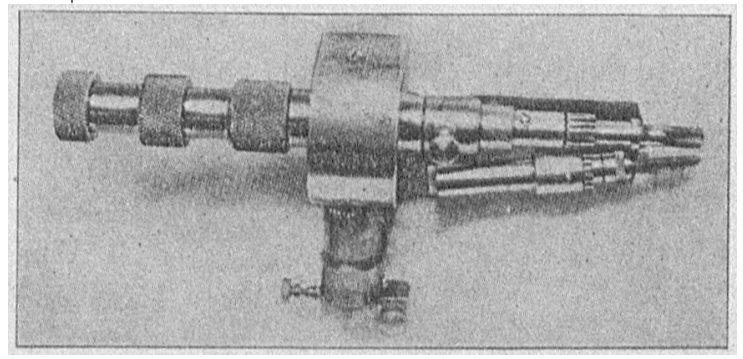

Fio. .0.-Martel's attachment to author's electrical surgical outfit for skull work. The skull is drilled with the large blunt drill, which automaticully stops, the instant the inner table of the skull is pierced. The mechanism is so perfect that the dura is never injured. In experimental tests a piece of wet paper placed on the inside of a dry skull has never been damaged by drilling the skull over it. The skull flap is then turned up by inserting the com. panion cutting tool into the hole thus made (see Fig. 5).

This automatic catch is a great improvement over the screw and screwdriver arrangement for holding the cutting instruments as used on the Hartley-Kenyon motor. In certain plastic work, especially fracture work, it may be necessary at one operation to employ several different cutting tools, - such as two sizes of single saws, twin 
saw, different sized drills, and surgical lathe,and also to interchange these several times. The automatic catch permits of almost as speedy a change of motor tool as of hand instruments, and is a most important feature of the outfit. As far as the author is aware, this is the first automatic catch to be incorporated into an electric motor surgical outfit, and it is almost indispensable to rapid work. Then, again, the screwdriver is a source of danger to the operator's gloved hand, because while loosening or tightening the screw, the motor shaft may turn, allowing the screw driver to push by and puncture the surgeon's glove.

When the motor tool is cutting, the handle,which is placed at a right angle to the long axis of the motor,-is held in the operator's right hand; the base of the motor is grasped in the left hand, and the right foot manipulates the foot switch, which is placed on the floor beside the operating table, at a place convenient for the operator's foot. If found necessary, the position of the motor and the hands may be reversed

\section{THE MANAGEMENT OF BREAST FEED- ING, WITH CASE REPORTS.*}

By C. K. Johnson, M.D., Burunaton, Vtr.

Instructor in Pediatrics, Oniversit/l of Vermont.

IT would be presumptuous on my part to attempt to give this group of pediatricians many new points on breast feeding, but this is a subject of much interest to me, and I thought that this short paper, even if much was a restatement of old observations, might stimulate in yourselves and more especially through you the general practitioner and the laity a more keen appreciation of the value of breast feeding. Almost daily I see infants put on the bottle, when with a little tact and patience I believe many of them could have with much benefit remained at the breast fully or partly for some weeks longer. longer.

One would judge from the numerous articles written on artificial feeding and the scarcity of them on breast feeding that everyone was supposed to know all about the natural method. In fact, do we not over-estimate our ability to adapt artificial food to infants? During my post-graduate work it has always seemed to me that breast feeding did not receive its deserved amount of time. Much depends upon the general practitioner and his attitude, as with him rests the responsibility of ascertaining sometime previous to the expected date of delivery that the breasts and nipples are in good condition. any sunken nipples receiving appropriate treatment at this time. He should also inquire as to the mother's habits, digestion, condition of the

- Read before the New England Pediatric Soclety, March 26, 1915. bowels, etc., as these all have an important bearing on successful nursing, and the prospective mother should be impressed with their importance.

I recently saw an infant, the first child, put on the bottle because of sunken nipples, which could undoubtedly have been prepared for their natural function had the necessary precautions been taken earlier.

One frequently sees a mother try to nurse her infant for two or three weeks. Then the breast milk becomes deficient. This occurs because the mother is tired out by her new duties, from lack of sleep and by seeing her infant losing in weight. The mental attitude has an unfavorable influence on the milk secretion, and after a little time, of her own initiative or by the advice of a physician, the infant is put on a bottle.

Dr. Griffith has well said that the adjustment of equilibrium between the mother's milk and the infant's digestion should be awaited and no haste made to give up the natural food until we are well satisfied that a change should be made.

Lucy Nash says that few mothers understand that the baby's cry during the first two or three days before the flow of milk becomes established, is not a cry of hunger, but a natural process for the full expansion of the lungs. In consequence they become nervous and get into a nervous state which affects the milk supply unfavorably.

Very recently a mother told me that she wanted to nurse her infant, then six days old. She was giving the bottle four or five times a day until the breasts became astive. The breast milk was slow in coming as might be expected I advised that all artificial food be stopped and that the infant be put to the breast at regular intervals. A report three days later said that the breast supply was sufficient and the infant contented.

The breast milk is often said not to agree with the infant. Very frequently, however, the milk is not analyzed, and even if this is done it may be misleading owing to the method of obtaining the sample to be analyzed. I recall one case where the laboratory report said that the milk was very poor and insufficient to nourish any infant. The infant, however, remained at the breast and continued to thrive. I find that the majority of general practitioners do not appreciate the marked variation in fat percentages between the first and last milk obtained from the breast. My cases reported in this paper well show this variation. In one instance in a multipara I emptied one breast with a breast pump, saving the milk in four consecutive samples, the analysis of which follows:-

$\begin{array}{lccrrrr} & \text { Fat. } & \text { Proteid. } & \text { Sugar. } & \text { Ash. } & \begin{array}{r}\text { Total } \\ \text { Solids. }\end{array} & \text { Water. } \\ \text { No. 1 } & 2.23 & .98 & \mathbf{6 . 6 0} & .17 & \mathbf{9 . 9 8} & \mathbf{9 0 . 0 2} \\ \text { No. 2 } & \mathbf{4 . 3 2} & 1.07 & \mathbf{7 . 1 6} & .19 & \mathbf{1 2 . 7 4} & \mathbf{8 7 . 2 6} \\ \text { No. 3 } & \mathbf{6 . 8 4} & 1.03 & \mathbf{5 . 5 0} & .16 & \mathbf{1 3 . 5 3} & \mathbf{8 6 . 4 7} \\ \text { No. 4 } & \mathbf{7 . 9 2} & 1.12 & - & - & - & -\end{array}$

It is needless for me to mention the relation of infant mortality to breast feeding. It might, 